\title{
Posturographic Analysis in the Elderly with and without sensorineural Hearing Loss
}

\author{
Daiane Soares de Almeida Ciquinato ${ }^{10}$ Marcelo Yugi Doi ${ }^{1}$ Rubens A. da Silva ${ }^{2,3}$ \\ Márcio Rogério de Oliveira ${ }^{2}$ André Wilson de Oliveira Gil ${ }^{4} \quad$ Luciana Lozza de Moraes Marchiori ${ }^{1}$ \\ 1 Pitagoras Unopar University, Stricto Sensu Graduate Program in \\ Rehabilitation Science UEL-UNOPAR, Londrina, Parana, Brazil \\ 2 Laboratory of Functional Evaluation and Human Motor Performance \\ (LAFUP) - UNOPAR, Professional Master's in Physical Exercise in \\ Health Promotion, Londrina, Parana, Brazil \\ ${ }^{3}$ Department des Sciences de la Sante, Programme de physiothéapie de \\ l'Université McGill offert en extension - a l'Université du Québec à \\ Chicoutimi (UQAC), Centre de recherche Intersectoriel en santé durable - \\ UQAC, Laboratoire de recherche BioNR - UQAC, Saguenay, Québec, Canada \\ ${ }^{4}$ Department of Physical Education, University State of Londrina, \\ (UEL), Londrina, Parana, Brazil \\ Int Arch Otorhinolaryngol 2020;24(4):e496-e502. \\ Address for correspondence Daiane Soares de Almeida Ciquinato, \\ Master's in Rehabilitation Science, Av. Paris, 675, Londrina, \\ PR, 86041-120, Brazil (e-mail: ciquinato19@gmail.com).
}

\begin{abstract}
Keywords

- aging

- postural balance

- rehabilitation

- sensorineural hearing loss
\end{abstract}

Introduction Sensorineural hearing loss (SNHL) is a serious public health problem. Some evidence suggests a significant relationship between SNHL and balance disorders. The inability to maintain balance associated with SNHL while standing further increases the risk of falls among older people.

Objective To investigate the association between SNHL on the postural balance in elderly individuals of both genders.

Methods The sample consisted of 247 (166 women) physically independent elderly individuals, (mean age $=68.4 \pm 6.0$ ). The instruments used were the anamnesis and the pure tone audiometry for hearing loss, and for balance a force platform based in measures of center of pressure area and of sway velocity in the anteroposterior and mediolateral directions. Results Presence of hearing loss ( $\mathrm{HL}$ ) was observed in $68 \%$ of the participants. We observed a significant association between SNHL and characteristics of balance between the groups with and without HL for center of pressure $(C O P)$ area $(p=0.010)$, anteroposterior velocity $(p=0.001)$ and mediolateral velocity $(p=0.020)$. There was a significant difference between the gender groups for center of pressure area $(p=0.004)$, anteroposterior velocity $(p=0.001)$ and mediolateral velocity $(p=0.001)$ with better performance in the female group. Amongst men, there was a difference between the ones with $\mathrm{HL}$ and those without it, for COP area $(p=0.049)$.

Conclusion In the present study, elderly individuals with SNHL exhibited more instability on the postural balance, and elderly men presented worse results in the test.

\section{Introduction}

The population of the world is aging rapidly. Therefore, awareness of sensory impairments in elderly individuals is crucial. Sensorineural hearing loss (SNHL) has a prominent impact on quality of life. Understanding the prevalence and impact of this impairment is important to help patients preserve and maintain a good quality of life. ${ }^{1}$

The prevalence of SNHL in the elderly is greater than in other age groups. In a Brazilian study with a total of 498 elderly subjects with a median age of 69 years were evaluated, sensorineural hearing loss (SNHL) was more prevalent (66.26\%) of received

March 29, 2019

accepted

December 3, 2019
DOI https://doi.org/

10.1055/s-0040-1701271. ISSN 1809-9777.
Copyright (e) 2020 by Thieme Revinter

Publicações Ltda, Rio de Janeiro, Brazil
License terms

()ㅇ (1) $\circledast$ 
most frequently with bilateral hearing loss of $91.56 \%$ and $26.50 \%$ with mild degree. ${ }^{2}$

The balance is guaranteed through the action of the postural control system, with integration of the three sensorimotor subsystems: vision, proprioception and vestibular. These sensory subsystems capture information from the external environment to be sent to the central nervous system (CNS), which processes, integrates, plans and generates a motor response of adequate postural adjustment through the action of the neuromuscular system. Biomechanically, balance requires the maintenance of the center of gravity (CG) within the base of support during static and dynamic situations of human movement. ${ }^{3}$

The anatomical proximity between the auditory and vestibular systems provides an interrelation. When the auditory system is compromised, there may be a pathological change in the vestibular system. ${ }^{4}$ Previous studies have demonstrated the contribution of the auditory system to postural balance, providing spatial orientation clues with great speed and accuracy. ${ }^{5,6}$ Hearing provides acoustic information about the environment, enabling the individual to notice and avoid environmental irregularities that could cause falls. ${ }^{7}$

Previous studies have found an association between the degrees of hearing loss (HL) and postural instabilities and balance changes in children with SNHL. These studies showed that the larger the degree of HL, the greater the postural instabilities and balance changes in children with SNHL. ${ }^{8-12}$ In adults and in the elderly with and without HL, changes in postural balance were also found in these populations. $^{6,13,14}$ The same is true for individuals with HL when fitted with a hearing aid ${ }^{15,16}$ or cochlear implant users with good hearing performance. ${ }^{17,18}$ However, these studies in the elderly did not compare this relationship between genders.

The balance involves the complex integration and coordination of multiple body systems, including the vestibular, the visual, the auditory, and the motor systems. Among elderly make poorer use of visual and vestibular information there is need greater help from the auditory system for maintaining postural balance. ${ }^{1,3,19,20}$ Therefore, the reason for conducting the present research was to investigate the association between SNHL on postural balance in the elderly of both genders.

\section{Methods}

This was a cross-sectional study. The sample of the present research was selected by convenience from an interdisciplinary project called the ELLO Project (Study on Aging and Longevity) project, which was developed at the University North of Parana (UNOPAR), after approval by the Research Ethics Committee of that institution (Process number PP/0070/09).

Additional information is available at http://www2. unopar.br/sites/eelo/.

The sample was randomly stratified taking into account the five regions of the city. From a population of 43,610 seniors enrolled in 38 community health centers from the urban area of Londrina, the calculated sample was composed of 385 individuals. Taking into account probable losses in the population, the sample was increased, reaching 519 individuals, of which $15 \%$ were from the central region, $27 \%$ from the northern region, $23 \%$ from the southern region, $19 \%$ from the eastern region and $16 \%$ from the western region. A sampling error of $5 \%$ and a power of 0.80 were considered for the calculation. ${ }^{21}$

The inclusion criteria consisted of age $>60$ years old, independent life and functional status ratings at levels 3 and 4 , as proposed by Spirduso. ${ }^{22}$ The exclusion criteria consisted of those with tinnitus caused by acute problems (such as acute otitis media or stoppers cerumen), people with limitations to the carrying out of the audiometric testing (such as cognitive impairment or inconsistent responses, those who presented physical and sensory limitations, with impediment to perform balance tests, such as inability to understand and comply with simple verbal commands and/or inability to adopt the requested positions; those with severely impaired visual acuity and disabling activities of daily living; those who had orthopedic disorders, with limited movement or use of lower limb prostheses; those with central vestibular dysfunction, reported by the participant; report of alcohol intake 24 hours before the evaluation; and use of drugs acting on the CNS or on the vestibular system 48 hours before the evaluation.

Of the 519 elderly who were recruited, 21 did not attend audiometric assessments, 1 was excluded due to tinnitus caused by acute otitis media, 4 due to inconsistent responses in the audiometric test, 3 due to lower limb prosthesis use, 2 for reporting of alcohol intake, 114 for inability to remain in the requested position, and 127 missed the posturography assessments after the third appointment. Thus, 247 (166 women) physically independent elderly volunteers participated in the study.

The routine audiological anamnesis used at the Audiology Clinic of UNOPAR was applied in the present study. The anamnesis is based on the protocol for anamnesis by Miller, ${ }^{23}$ which consists in otoscopy to examine the external acoustic meatus and the tympanic membrane and pure tone audiometry, considered the gold standard to evaluate the auditory threshold in adults, at the frequencies of $250-8,000 \mathrm{kHz}$ with presentation of pure tones, initially using $30 \mathrm{dBHL}$ at $1,000 \mathrm{~Hz}$. The result was noted in a record form of pure tone audiometry used in the routine care of that sector, and subsequently entered into the database in the program WinAudio Software (Curitiba, Parana, Brazil) to be stored and printed for the patient.

The study included only the elderly with normal hearing and SNHL evidenced by threshold tone audiometry, regardless of the degree of loss. The classification used to determine HL was the degree, considering individuals without HL those whose tritone average was up to $25 \mathrm{~dB}$, and with $\mathrm{HL}$ those with tritone average $>26 \mathrm{~dB} .^{24}$ Afterwards, the participants were divided into subgroups: normal hearing $(\mathrm{NH})$; normal hearing with high-frequency hearing loss (HFHL) including $6,000 \mathrm{~Hz}$ and $8,000 \mathrm{~Hz}$; sensorineural hearing loss (SNHL) and or mixed hearing loss (MHL). Few elderly patients had MHL $(\mathrm{n}<20)$, as this type of $\mathrm{HL}$ also has a sensorineural component, so these data were allocated together with those who presented SNHL. No participant was identified with conductive HL and did not use a hearing aid or cochlear implant.

The balance assessment was performed in the Laboratory of Functional Assessment and Human Motor Performance 
(LAFUP). All of the participants were evaluated on a force platform BIOMEC400 (EMG System do Brasil Ltda., São José dos Campos, SP, Brazil). All the force signals recorded by the platform are filtered by a second-order bypass filter of $35 \mathrm{~Hz}$ (Butterworth filter) to eliminate the electrical noises. ${ }^{25}$ The platform is able to quantify the distribution of vertical force on four spots for analysis of postural balance. The platform signs of reaction, after filtered, are analyzed by the MATLAB (Mathworks, Natick, MA, United States) routines program by the system software itself, which extracts the main parameters of postural balance: the $95 \%$ confidence ellipse area of center of pressure (A-COP) and sway velocity of the center of pressure (COP) in both directions of movement (anteroposterior [AP]; and mediolateral $[\mathrm{ML}]){ }^{26}$ The ellipse area/surface quantifies 90 or $95 \%$ of the total area covered in the ML and AP directions using an ellipse to fit the data. It is considered to be an index of overall postural performance the smaller the surface, the better the performance. Velocity is calculated by dividing the COP excursion by the trial time. One can consider the ML and AP components or the resultant velocity. It reflects the efficiency of the postural control system (the smaller the velocity, the better the postural control). ${ }^{27}$ The elderly participants were familiarized with the equipment and with the experimental protocol.

The balance test occurred in a suitable environment, with individuals instructed to remain in a one-leg stance condition (lower limb preferred) on the force platform, with bare feet, arms loose and relaxed beside the body and the head positioned horizontally relatively to the ground. The test was performed using the experimental protocol, eyes open, requesting that individuals observe a target (black cross $=14.5 \mathrm{~cm}$ high $\times 14.5 \mathrm{~cm}$ wide $\times 4 \mathrm{~cm}$ thick) on the wall placed 2 meters away at eye level. Three trials of 30 seconds were performed, with 30 seconds rest between them. The average of the three measurements was used for analysis. ${ }^{26}$

For the statistical analysis, IBM SPSS Statistics for Windows, Version 20 (IBM Corp., Armonk, NY, USA) was used. The parametric distribution of the data was verified by the Shapiro-Wilk test, and since there was no assumption of normality, the Mann-Whitney test and the Kruskal-Wallis test were used. The left ears were selected because they had the highest number of SNHL. Significance was set at $p<0.05$.

Estimates of effect size for nonparametric tests were also performed. 28,29

The effect size for the Mann-Whitney test was calculated using the equation: $r=Z / \sqrt{n}$, where " $r$ " is the correlation coefficient, " $Z$ " is the standardized value for the $U$-value and " $n$ " is the number of observations. The interpretation of the calculated $r$-value coincides with the one for the Pearson correlation coefficient $(r) .{ }^{28,29}$

For the Kruskal-Wallis H-test, the epsilon-squared estimate $\left(E_{r}^{2}\right)$ was utilized of effect size can be calculated, using the equation: $E_{r}{ }^{2}=H /\left(n^{2}-1\right) /(\mathrm{n}+1)$; where " $E_{r}^{2}$ " is coefficient that assumes the value from 0 (indicating no relationship) to 1 (indicating a perfect relationship); " $H$ " is the value obtained in the Kruskal-Wallis test and " $n$ " is the total number of observations. ${ }^{28}$
Table 1 Descriptive data of the sample $(n=247)$

\begin{tabular}{|c|c|}
\hline GENERAL CHARACTERISTICS & \\
\hline \multicolumn{2}{|l|}{ Groups } \\
\hline With hearing loss & $n=167(67.6 \%)$ \\
\hline Without hearing loss & $n=80(32.4 \%)$ \\
\hline \multicolumn{2}{|l|}{ Types of hearing } \\
\hline $\mathrm{NH}$ & $n=29(11.7 \%)$ \\
\hline HFHL & $n=51(20.6 \%)$ \\
\hline $\mathrm{SNHL} / \mathrm{MHL}$ & $n=167(67.6 \%)$ \\
\hline \multicolumn{2}{|l|}{ Gender } \\
\hline Female & $n=166(67.2 \%)$ \\
\hline Male & $n=81(32.9 \%)$ \\
\hline \multicolumn{2}{|l|}{ BMI } \\
\hline Low weight $\left(<23 \mathrm{~kg} / \mathrm{m}^{2}\right)$ & $n=42(17 \%)$ \\
\hline Normal weight $\left(23<\mathrm{BMI}<28 \mathrm{~kg} / \mathrm{m}^{2}\right)$ & $n=105(42.5 \%)$ \\
\hline Pre-obesity $\left(28<\mathrm{BMI}<30 \mathrm{~kg} / \mathrm{m}^{2}\right)$ & $n=35(14.2 \%)$ \\
\hline Obesity $\left(\mathrm{BMI}>30 \mathrm{~kg} / \mathrm{m}^{2}\right)$ & $n=65(26.3 \%)$ \\
\hline \multicolumn{2}{|l|}{ Age range (years old) } \\
\hline 60-64 years old & $n=72(29.2 \%)$ \\
\hline $65-74$ years old & $n=136(55.1 \%)$ \\
\hline$\geq 75$ years old & $n=39(15.2 \%)$ \\
\hline Mean \pm standard deviation & $68.4 \pm 6.0$ \\
\hline
\end{tabular}

Abbreviations: BMI, body mass index; HFHL, normal hearing with highfrequency hearing loss; $\mathrm{NH}$, normal hearing; $\mathrm{SNHL} / \mathrm{MHL}$, sensorineural hearing loss/mixed hearing loss.

Table 2 Difference between groups with hearing loss and without hearing loss

\begin{tabular}{|l|l|l|l|}
\hline & $\begin{array}{l}\text { With } \\
\text { hearing loss } \\
\mathrm{N}=167\end{array}$ & $\begin{array}{l}\text { Without } \\
\text { hearing loss } \\
\mathbf{N}=80\end{array}$ & $\begin{array}{l}\text { - } \text {-value } \\
\text { (Mann-Whitney) }\end{array}$ \\
\hline $\begin{array}{l}\text { A-COP } \\
\left(\mathrm{cm}^{2}\right)\end{array}$ & $12.69[14.66]^{\mathrm{a}}$ & $9.98[7.45]$ & $\begin{array}{l}p=0.010^{*} \\
\mathrm{r}=0.2^{\mathrm{b}}\end{array}$ \\
\hline $\begin{array}{l}\text { VEL-AP } \\
(\mathrm{cm} / \mathrm{s})\end{array}$ & $3.78[2.46]$ & $3.24[1.53]$ & $\mathrm{p}=0.001^{*}$ \\
\hline & & & $\mathrm{r}=0.2^{\mathrm{b}}$ \\
\hline $\begin{array}{l}\text { VEL-ML } \\
(\mathrm{cm} / \mathrm{s})\end{array}$ & $4.02[1.97]$ & $3.67[1.86]$ & $\mathrm{p}=0.020^{*}$ \\
\hline & & & $\mathrm{r}=0.1^{\mathrm{b}}$ \\
\hline
\end{tabular}

Abbreviations: A-COP, center of pressure area; VEL-AP, velocity in anteroposterior direction; VEL-ML, velocity in mediolateral direction. ${ }^{a}$ (values in median and interquartile range).

beffect size.

*(statistically significant difference).

\section{Results}

The descriptive data of the participants are shown in -Table 1. A total of 247 subjects were included in the analyses. The included participants had a mean age of $68 \pm 6$ years old, with a larger number of women (67\%). Of 
Table 3 Difference between center of pressure variables and types of hearing

\begin{tabular}{|c|c|c|c|c|}
\hline & $\begin{array}{l}\mathrm{NH} \\
\mathrm{N}=29\end{array}$ & $\begin{array}{l}\mathrm{HFHL} \\
\mathrm{N}=41\end{array}$ & $\begin{array}{l}\mathrm{SNHL} / \mathrm{MHL} \\
\mathrm{N}=167\end{array}$ & $\begin{array}{l}\text { p-value } \\
\text { (Kruskall-Wallis) }\end{array}$ \\
\hline \multirow[t]{2}{*}{$\begin{array}{l}\text { A-COP } \\
\left(\mathrm{cm}^{2}\right)\end{array}$} & $\begin{array}{l}11.05 \\
{[7.51]^{\mathrm{a}}}\end{array}$ & $\begin{array}{l}9.68[ \\
7.71]\end{array}$ & $\begin{array}{l}12.15 \\
{[13.69]}\end{array}$ & $p=0.052$ \\
\hline & & & & $E_{r}^{2}=0.02^{\mathrm{b}}$ \\
\hline \multirow[t]{2}{*}{$\begin{array}{l}\text { VEL-AP } \\
(\mathrm{cm} / \mathrm{s})\end{array}$} & $\begin{array}{l}3.44 \\
{[1.39]}\end{array}$ & $\begin{array}{l}3.10 \\
{[1.65]}\end{array}$ & $\begin{array}{l}3.78 \\
{[2.46]}\end{array}$ & $p=0.006^{*}$ \\
\hline & & & & $E_{r}^{2}=0.03^{b}$ \\
\hline \multirow[t]{2}{*}{$\begin{array}{l}\text { VEL-ML } \\
(\mathrm{cm} / \mathrm{s})\end{array}$} & $\begin{array}{l}3.58 \\
{[1.84]}\end{array}$ & $\begin{array}{l}3.73 \\
{[2.06]}\end{array}$ & $\begin{array}{l}4.02 \\
{[1.97]}\end{array}$ & $p=0.092$ \\
\hline & & & & $E_{r}^{2}=0.01^{\mathrm{b}}$ \\
\hline
\end{tabular}

Abbreviations: A-COP, center of pressure area; $\mathrm{HFHL}$, normal hearing with high-frequency hearing loss; NH, Normal Hearing; $\mathrm{SNHL} / \mathrm{MHL}$, sensorineural hearing loss/mixed hearing loss; VEL-AP, velocity in anteroposterior direction; VEL-ML, velocity in mediolateral direction. a(values in median and interquartile range).

b (effect size).

*(statistically significant difference).

Table 4 Difference between balance variables and gender

\begin{tabular}{|c|c|c|c|}
\hline & $\begin{array}{l}\text { Female } \\
(n=166)\end{array}$ & $\begin{array}{l}\text { Male } \\
(n=80)\end{array}$ & $\begin{array}{l}\text { p-value } \\
\text { (Mann-Whitney) }\end{array}$ \\
\hline \multirow[t]{2}{*}{$\begin{array}{l}\text { A-COP } \\
\left(\mathrm{cm}^{2}\right)\end{array}$} & $\begin{array}{l}10.71 \\
{[9.59]^{\mathrm{a}}}\end{array}$ & $\begin{array}{l}14.50 \\
{[13.93]}\end{array}$ & $p=0.004^{*}$ \\
\hline & & & $\mathrm{r}=0.2^{\mathrm{b}}$ \\
\hline \multirow[t]{2}{*}{$\begin{array}{l}\text { VEL-AP } \\
(\mathrm{cm} / \mathrm{s})\end{array}$} & $\begin{array}{l}3.27 \\
{[1.59]}\end{array}$ & $\begin{array}{l}4.54 \\
{[2.68]}\end{array}$ & $p=0.001^{*}$ \\
\hline & & & $r=0.3^{b}$ \\
\hline \multirow[t]{2}{*}{$\begin{array}{l}\text { VEL-ML } \\
(\mathrm{cm} / \mathrm{s})\end{array}$} & $\begin{array}{l}3.70 \\
{[1.64]}\end{array}$ & $\begin{array}{l}4.56 \\
{[2.51]}\end{array}$ & $p=0.001^{*}$ \\
\hline & & & $r=0.3^{b}$ \\
\hline
\end{tabular}

Abbreviations: A-COP, center of pressure area; VEL-AP, velocity in anteroposterior direction; VEL-ML, velocity in mediolateral direction. a(values in median and interquartile range).

b(effect size).

*(statistically significant difference). the total, $68 \%$ presented hearing loss; of these, 98 (59\%) were aged between 65 and 74 years old.

There was a significant difference for COP variables between the groups with and without HL (see - Table 2). There was a significant difference between the three subgroups only for the Velocity in anteroposterior direction (VEL-AP) $(p=0.006)$ in the SNHL/MHL group (see - Table 3). The Kruskal-Wallis test was performed with pairs comparison and analyses post-hoc Dunn test demonstrated difference between SNHL / MHL group and HFHL group ( $\mathrm{p}$ adjusted $=0.012$ ).

Regarding gender, there was a significant difference between the groups in all COP variables (see - Table 4), and the male group showed a mean rank higher than the female group (female $=116.40$ and male $=144.15$ ). In the adjusted analysis for gender demonstrated in - Table 5, there was no significant difference for females with and without HL and the COP variables $(p>0.05)$. For the male group, there was a difference between the groups with and without HL for A$\operatorname{COP}(p=0.049)$ for the HL group by mean rank of the MannWhitney test (normal $=30.25$; hearing loss $=43.06$ ). There was no difference for the other variables VEL-AP $(p=0.061)$ and Velocity in mediolateral direction (VEL-ML) $(p=0.536)$.

Analyses for the age range group were performed considering the groups with and without HL and the balance variables, but there was no significant difference ( $p>0.05)$. Also, no differences were found for BMI and balance (date already published ref. ${ }^{30}$ ). Effect size estimates were found between 0.1 and 0.3 for all analyzed variables, demonstrating a small effect size (shown in - Table 2-5). The analysis of effect sizes was taken into account for analyzing and understanding of these results that measures the small strength of the relationship between these variables on a numeric scale.

\section{Discussion}

The main objective of the study was to investigate the association between SNHL on postural balance in the elderly of both genders. The findings have shown that the majority of the elderly (67.6\%) presented HL, and the group with such loss presented a significant difference and inferior performance in posturography when compared with the group without loss in all variables of the COP. In addition, although the general sample consisted of a greater number of females,

Table 5 Difference between balance variables, hearing loss and gender

\begin{tabular}{|l|l|l|l|l|l|l|}
\hline & \multicolumn{2}{|l|}{ Female } & \multicolumn{2}{l|}{ Male } \\
\cline { 2 - 7 } & $\begin{array}{l}\text { With HL } \\
(\boldsymbol{n}=103)\end{array}$ & $\begin{array}{l}\text { Without HL } \\
(\boldsymbol{n}=63)\end{array}$ & $\begin{array}{l}\text { p-value } \\
(\text { Mann-Whitney) }\end{array}$ & $\begin{array}{l}\text { With HL } \\
(\boldsymbol{n}=64)\end{array}$ & $\begin{array}{l}\text { Without HL } \\
(\boldsymbol{n}=16)\end{array}$ & $\begin{array}{l}\boldsymbol{p} \text {-value } \\
(\text { Mann-Whitney) }\end{array}$ \\
\hline A-COP $\left(\mathrm{cm}^{2}\right)$ & $11.17[12.79]$ & $9.95[7.41]^{\mathrm{a}}$ & $p=0.339$ & $15.1[14.67]$ & $10.6[7.43]$ & $\begin{array}{l}p=0.049^{*} \\
\mathrm{r}=0.2^{\mathrm{b}}\end{array}$ \\
\hline VEL-AP $(\mathrm{cm} / \mathrm{s})$ & $3.38[1.64]$ & $3.04[1.43]$ & $p=0.166$ & $4.75[2.51]$ & $3.78[2.20]$ & $p=0.061$ \\
\hline VEL-ML $(\mathrm{cm} / \mathrm{s})$ & $3.91[1.56]$ & $3.60[1.83]$ & $p=0.175$ & $4.53[2.53]$ & $4.57[1.87]$ & $p=0.536$ \\
\hline
\end{tabular}

Abbreviations: A-COP, center of pressure area; HL, hearing loss; VEL-AP, velocity in anteroposterior direction; VEL-ML, velocity in mediolateral direction.

${ }^{a}$ (values in median and interquartile range).

beffect size).

*(statistically significant difference). 
the subgroup of males reported worse results in the test than females.

The process of human aging has morphological and physiological changes, increasing the risk of postural balance alterations and HL. The physiological decline of the human body generated by aging can occur in several ways, including bone density and muscle mass reduction, increased postural instability, impairment of visual and auditory capacity. ${ }^{31}$ Hearing loss known as presbycusis can occur beginning in the middle age. It is usually neurosensory and bilateral and refers to the result of a long period of damage to the auditory system, a variety of physiological degenerations, including damage caused by exposure to noise, ototoxic agents and other disorders caused by different medical treatments. ${ }^{32-35}$

Although some studies about presbycusis demonstrate that $\sim 40 \%$ of individuals $>65$ years old suffer from presbycusis or age-related $\mathrm{HL}^{36}$ in our study we found a prevalence of $68 \%$ of elderly individuals with HL revealed by pure-tone audiometry. The high frequency of HL among the elderly in the present study corroborates those of another, which used the same methodology and concluded that the presence of SNHL was in $63.93 \%$ of the elderly participants. ${ }^{37}$ It is thought to be due to physiological aging processes, particularly as they affect the microvascular blood supply of the hair cells (sensory type), with resulting ischemia, hypoxia, and oxidative stress. These processes can also affect the ganglion cells (neural type) or the stria vascularis (metabolic type). ${ }^{36}$ These same factors can affect postural balance.

Our findings have demonstrated a significant difference between the groups with and without hearing loss in all COP variables. We have also found a difference in VEL-AP for the SNHL/MHL group in the adjusted analyses. These results are in line with other studies on the association between HL and balance. $^{32,38}$ In a study aiming at understanding whether HL could influence balance, in which 13 patients with moderate HL were assessed, differences were found in HL and increased posturographic measures, especially the sagittal sway, underlining a reduced postural control in people with hearing impairments. Hearing loss may be associated with an increased risk of falls. ${ }^{32}$

The results of the present study indicate that SNHL is primarily associated with balance, since the groups with loss and without loss differed in all COP variables. A recent systematic review found a significant positive association between $\mathrm{HL}$ in older people and several objective measures of postural control, even after controlling for major covariates such as body mass index (BMI), physical activity, comorbidities, and smoking status. ${ }^{39}$ The COP velocity reflects the efficiency of the postural control system in characterizing the net neuromuscular activity necessary to maintain balance and has been considered as the most reliable measure among trials. ${ }^{27}$

Regarding gender, an association related to balance has been found, with the subgroup of men presenting worse balance. In contrast with the present report, a study with a population of 29 individuals (of these, 92\% with SNHL) has verified the effectiveness of an audio-biofeedback (ABF) system for improving balance in patients with bilateral vestibular loss (BVL). Participants with BVL had significantly larger postural sway than unaffected participants. Those with BVL, while using ABF, decreased the sway area by $23 \pm 4.9 \%$ and trunk accelerations by $46 \pm 9.9 \%$, and increased the time spent within \pm 1 degrees of the sway threshold by $195 \pm 34.6 \%$. Audio-biofeedback improved the stance stability of participants with BVL by increasing the amount of postural corrections. However, in the aforementioned study, there has also been a relation to the variable balance velocity ML, but women with SNHL presented worse results. $^{40}$

On the other hand, Dillon et $a l,{ }^{41}$ who evaluated a nationwide representative sample of elderly Americans, have shown that elderly men are more likely than elderly women to have HL and loss of foot sensitivity, which may influence postural balance. This may justify the findings in our study concerning the male population. Our results are likely to be due to seemingly higher exposure to noise by men since it is more common in men than in women, regardless of occupational or leisure noise exposure. ${ }^{42,43}$

Although there has been no difference among women, the present report is in agreement with the studies in the area that suggest greater care with hearing health in the female elderly population. Females are considered in the literature as the most longevous and most concerned with hearing impairment, as well as with their general health, in comparison with men. ${ }^{44,45}$

It is known that hearing loss affects 1 in every 3 persons $>65$ years old, and every other person $>75$ years old, in the United States. ${ }^{46}$ However, in the present study, we have not found any difference in adjusted analyses for the age range between imbalance and SNHL in the elderly. This was observed both in those with HL and in those without HL. The age group was categorized in the present study because another paper from our research group with the same population showed a significant difference between HL and the age groups. ${ }^{2}$ However, the data did not demonstrate the same association with postural balance. Possibly, the process of sensory reweighting has actuated by reallocating the essential sensory information for the less affected body system. The postural control system receives the available sensory information and selects the most relevant or precise sensory information within a given context, providing different weights to this information during the maintenance of upright posture. ${ }^{47}$ In addition, the participants were physically independent, which may have contributed to not finding significant differences between the age ranges.

Research provides a possible explanation to elucidate the contribution of hearing to the postural control system. The differential explanation considers that when the head moves, the acoustic signals in both ears may be altered. The CNS notices that movement in one direction is increasing and sends a message to the body to adjust in the opposite direction. Thus, in an attempt to reduce the change in the acoustic signal, the participant reduces head and body movements. ${ }^{48}$ This would be a possible explanation for the findings of the present study with the elderly with normal hearing presenting lower A-COP, VEL-AP and VEL-ML values. 
Postural control disorders continue to be an important contributing factor to morbidity and mortality among the elderly, so it is very important to check the causes and factors associated with imbalance. In the present study, the group with HL presented worse performance in the test in all COP variables. From these findings, we verified that HL changes the postural balance. Probably, the findings of this research are related to the aging of the auditory system and changes in balance due to age. Probably, the use of hearing aids may help balance due to correction of feedback because the use of additional sensory information generated by the hearing aid can promote improvement of functional hearing and balance performance in the elderly population, but further studies with users of hearing aids are necessary.

\section{Limitations of the Study}

Our study had some limitations that should be considered. First: a potential limitation of our study stems from its patients not having been separated regarding the degree of HL. Because of these limitations, either future researches should be performed, by case-control or population-based studies, to complement and confirm association rates of $\mathrm{HL}$ and balance among the elderly. Second: the assessment of postural balance was performed in a single posture of the footrest, with eyes open. In other sensory conditions, it is possible to find different results; Third: In this part of the study, the vestibular function was not evaluated. Thus, further researches are necessary in order to investigate the mechanism of this association using longitudinal data with a prospective design.

\section{Future Perspectives}

These results suggest further exploration to determine the association between sensorioneural hearing loss and postural balance in elderly. Such studies could verify whether early interventions for prevention and minimization of the effects of HL would help reducing imbalance in patients at increased risk, thus influencing the extent to which imbalance is experienced as troubling and, therefore, problems that refer to quality of life in association with it. As inner ear damage is generally irreversible, early diagnosis allowing prompt treatment is important.

A thorough history and examination will often provide a clear direction as to the diagnosis. A correct diagnosis allows treatment for many of the peripheral and central vestibular disorders. Audiovestibular rehabilitation should be initiated early in the disease process to prevent chronic symptoms. ${ }^{49}$ It is therefore necessary to implement programs for the prevention and monitoring of balance in the population of elderly people with HL. It is also necessary to schedule proper balance interventions among the elderly with HL to avoid falls that could increase the risk of morbidity and mortality. Further studies are suggested to elucidate if there is HL in relation to the stabilometric parameters of balance, due to the decreasing hearing ability in younger populations.

\section{Conclusion}

The present study has shown that elderly individuals with HL presented greater instabilities in the posturographic evaluation when compared with those without this sensorial deficit. Amongst men, there was a difference between the ones with $\mathrm{HL}$ and those without it, for the COP area. These results suggest further exploration to determine this association.

\section{Area}

Audiology.

Financial Assistance

FUNADESP.

Conflict of Interests

The authors have no conflict of interests to declare.

\section{References}

1 Rooth MA. The prevalence and impact of vision and hearing loss in the elderly. N C Med J 2017;78(02):118-120

2 Meneses-Barriviera CL, Bazoni JA, Doi MY, Marchiori LLM. Probable Association of Hearing Loss, Hypertension and Diabetes Mellitus in the Elderly. Int Arch Otorhinolaryngol 2018;22(04):337-341

3 Gribble PA, Hertel J. Effect of hip and ankle muscle fatigue on unipedal postural control. J Electromyogr Kinesiol 2004;14(06): 641-646

4 Parke S. O ouvido e a audição. São Paulo: Scipione; 1992

5 Stevens MN, Barbour DL, Gronski MP, Hullar TE. Auditory contributions to maintaining balance. J Vestib Res 2016;26(56):433-438

6 Viljanen A, Kaprio J, Pyykkö I, et al. Hearing as a predictor of falls and postural balance in older female twins. J Gerontol A Biol Sci Med Sci 2009;64(02):312-317

7 Kleiner AFR, Schlittler DXC, Sánchez-Arias MDR. The role of visual, vestibular, somatosensory and auditory systems for the postural control. Rev Neurocienc 2011;19(02):349-357

8 Melo RdeS, Lemos A, Macky CFST, Raposo MCF, Ferraz KM. Postural control assessment in students with normal hearing and sensorineural hearing loss. Rev Bras Otorrinolaringol (Engl Ed) $2015 ; 81(04): 431-438$

9 Melo RS. Gait performance of children and adolescents with sensorineural hearing loss. Gait Posture 2017;57:109-114

10 Melo RS, Lemos A, Raposo MCF, Belian RB, Ferraz KM. Balance performance of children and adolescents with sensorineural hearing loss: Repercussions of hearing loss degrees and etiological factors. Int J Pediatr Otorhinolaryngol 2018;110:16-21

11 Melo RS, Lemos A, Raposo MCF, Monteiro MG, Lambertz D, Ferraz KM. Repercussions of the hearing loss degrees and vestibular dysfunction on the static balance of children with sensorineural hearing loss. Hum Mov Sci 2019

12 Melo RS, Amorim da Silva PW, Souza RA, Raposo MCF, Ferraz KM. Comparação da posição da cabeça entre estudantes com audição normal e estudantes com perda auditiva neurossensorial. Int Arch Otorrinolaringol 2013;17:363-369

13 Kowalewski V, Patterson R, Hartos J, Bugnariu N. Hearing Loss Contributes to Balance Difficulties in both Younger and Older Adults. J Prev Med (Wilmington) 2018;3(02):12

14 Vitkovic J, Le C, Lee SL, Clark RA. The Contribution of Hearing and Hearing Loss to Balance Control. Audiol Neurotol 2016;21(04): 195-202

15 Weaver TS, Shayman CS, Hullar TE. The effect of hearing aids and cochlear implants on balance during gait. Otol Neurotol 2017;38 (09):1327-1332 
16 Negahban H, Bavarsad Cheshmeh Ali M, Nassadj G. Effect of hearing aids on static balance function in elderly with hearing loss. Gait Posture 2017;58:126-129

17 Greters ME, Bittar RSM, Grasel SS, Oiticica J, Bento RF. Hearing performance as a predictor of postural recovery in cochlear implant users. Rev Bras Otorrinolaringol (Engl Ed) 2017;83(01):16-22

18 Oikawa K, Kobayashi Y, Hiraumi H, Yonemoto K, Sato H. Body balance function of cochlear implant patients with and without sound conditions. Clin Neurophysiol 2018;129(10):2112-2117

19 Vieira ER, Palmer RC, Chaves PH. Prevention of falls in older people living in the community. BMJ 2016;353(01):i1419

20 Pajala S, Era P, Koskenvuo M, Kaprio J, Törmäkangas T, Rantanen T. Force platform balance measures as predictors of indoor and outdoor falls in community-dwelling women aged 63-76 years. J Gerontol A Biol Sci Med Sci 2008;63(02):171-178

21 Hayashi D, Gonçalves CG, Parreira RB, et al. Postural balance and physical activity in daily life (PADL) in physically independent older adults with different levels of aerobic exercise capacity. Arch Gerontol Geriatr 2012;55(02):480-485

22 Spidurso WW. Dimensões físicas do envelhecimento. Barueri: Manole; 2005

23 Miller MH. A integração dos achados audiológicos. In: Katz J (Org). Tratado de audiologia clínica. 3a ed. São Paulo: Manole; 1999:268-270

24 Davis H, Silverman SR. Hearing and deafness. 3rd ed. New York: Holt, Rinehart and Winston; 1970

25 Gil AWO, Oliveira MR, Coelho VA, Carvalho CE, Teixeira DC, da Silva RA Jr. Relationship between force platform and two functional tests for measuring balance in the elderly. Rev Bras Fisioter 2011;15(06):429-435

26 da Silva RA, Bilodeau M, Parreira RB, Teixeira DC, Amorim CF. Agerelated differences in time-limit performance and force platformbased balance measures during one-leg stance. J Electromyogr Kinesiol 2013;23(03):634-639

27 Paillard T, Noé F. Techniques and methods for testing the postural function in healthy and pathological subjects. BioMed Res Int 2015;2015:891390

28 Fritz CO, Morris PE, Richler JJ. Effect size estimates: current use, calculations, and interpretation.J Exp Psychol Gen 2012;141(01):2-18

29 Tomczak A, Tomczak E. The need to report effect size estimates revisited. An overview of some recommended measures of effect size. Trends Sport Sci 2014;1:19-25

30 Pereira C, Silva RAD, de Oliveira MR, Souza RDN, Borges RJ, Vieira ER. Effect of body mass index and fat mass on balance force platform measurements during a one-legged stance in older adults. Aging Clin Exp Res 2018;30(05):441-447

31 Leme GLM, Carvalho IF, Scheicher ME. Improvement of postural balance in elderly women with the use of additional sensory information. Fisioter Pesqui 2017;24(01):68-73

32 Thomas E, Martines F, Bianco A, et al. Decreased postural control in people with moderate hearing loss. Medicine (Baltimore) 2018; 97(14): 0244
33 Soto-Varela A, Rossi-Izquierdo M, Faraldo-García A, et al. Balance disorders in the elderly: does instability increase over time? Ann Otol Rhinol Laryngol 2016;125(07):550-558

34 Momensohn-Santos TM, Russo ICP. Prática da audiologia clínica. 8. ed. São Paulo: Cortez; 2011

35 Baraldi GS, Almeida LC, Borges ACC. Hearing loss in aging. Rev Bras Otorrinolaringol 2007;73(01):64-70

36 Zahnert T. The differential diagnosis of hearing loss. Dtsch Arztebl Int 2011;108(25):433-443, quiz 444

37 Meneses C, Mário MP, Marchori LLM, Melo JJ, Freitas ERFS Prevalência de perda auditiva e fatores associados na população idosa de Londrina, Paraná: estudo preliminar. Rev CEFAC 2010;12 (03):384-392

38 Siedlecka B, Sobera M, Sikora A, Drzewowska I. The influence of sounds on posture control. Acta Bioeng Biomech 2015;17(03): 96-102

39 Agmon M, Lavie L, Doumas M. The association between hearing loss, postural control, and mobility in older adults: A Systematic Review. J Am Acad Audiol 2017;28(06):575-588

40 Bruniera JRZ, Camiloti JF, Penha OM, Franco PPR, Silva RA Marchiori LLM. Análise comparativa do equilíbrio postural pela posturografia em pacientes com vertigem isolada ou associada com perda auditiva. Audiol Commun Res 2015;20(04): 321-326

41 Dillon CF, Gu Q Hoffman HJ, Ko CW. Vision, hearing, balance, and sensory impairment in Americans aged 70 years and over: United States, 1999-2006. NCHS Data Brief 2010;(31):1-8

42 Yamasoba T, Lin FR, Someya S, Kashio A, Sakamoto T, Kondo K. Current concepts in age-related hearing loss: epidemiology and mechanistic pathways. Hear Res 2013;303:30-38

43 Agrawal Y, Platz EA, Niparko JK. Prevalence of hearing loss and differences by demographic characteristics among US adults: data from the National Health and Nutrition Examination Survey, 1999-2004. Arch Intern Med 2008;168(14):1522-1530

44 Araujo TM, Iório MCM. Profile of the elderly population referred for hearing aid fitting in a public. Audiol Commun Res 2014;19 (01):45-51

45 Silva BSR, Sousa GB, Russo ICP, Silva JAPR. Caracterização das queixas, tipo de perda e tratamento de indivíduos idosos atendidos em uma clínica particular de Belém - PA. Arq Int Otorrinolaringol 2007;11(04):387-395

46 Vaisbuch Y, Santa Maria PL. Age-Related Hearing Loss: Innovations in Hearing Augmentation. Otolaryngol Clin North Am 2018; 51(04):705-723

47 Freitas Júnior P, Barela JA. Alterações no funcionamento do sistema de controle postural de idosos: uso da informação visual. Rev Port Cienc Desporto 2006;6(01):94-105

48 Zhong X, Yost WA. Relationship between postural stability and spatial hearing. J Am Acad Audiol 2013;24(09):782-788

49 Agrup C, Gleeson M, Rudge P. The inner ear and the neurologist. J Neurol Neurosurg Psychiatry 2007;78(02):114-122 